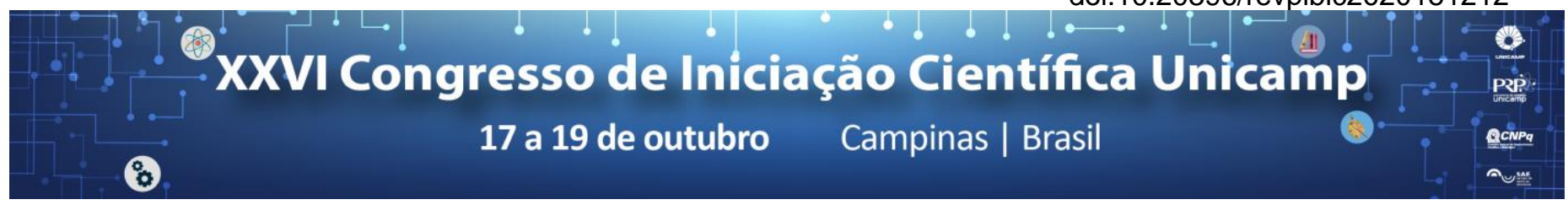

\title{
BIM aplicado na modelagem de trilhos para metrô
}

\author{
Renato C. Maruyama*, Regina Coeli Ruschel.
}

\section{Resumo}

O BIM é um novo método de trabalho que possibilita a representação digital das características geométricas e funcionais de um projeto durante todo o seu ciclo de vida. Como os projetos de infraestruturas possuem detalhes de vão de centímetros à quilômetros, o objetivo é modelar trechos representativos ao invés de representar todo o projeto. Foram modelados três trechos recorrentes em projetos de metrô, identificando adaptações, bibliotecas e parâmetros associados. O potencial de estimativa da ferramenta de quantificação do software Revit também foi analisado, bem como a eficiência e representatividade de componentes IFC (formato padrão de troca de informações) nos esquemas exportados.

Palavras-chave: BIM, metrô, quantificação

\section{Introdução}

O BIM é um termo originado do inglês que significa Building Information Modeling. Embora o termo building da sigla signifique prédio, ele também engloba as obras de infraestruturas, como túneis, pontes, rodovias, ferrovias, etc. Esses grandes projetos são complexos pois envolvem muitos profissionais, necessitam de alto investimento e alteram o ambiente ao redor. Por essas razões, a utilização do BIM trará benefícios como a estimativa de custos, o monitoramento e controle de cronogramas, além de facilitar a troca de informações entre os diversos atores envolvidos.

A adoção do BIM nas obras ferroviárias ainda é baixa, já que não existem ferramentas e terminologias específicas para definir alguns elementos, como lastro e dormente.

O objetivo geral desta pesquisa é demonstrar o uso de ferramenta BIM na modelagem de trilhos para metrô. Os objetivos específicos consistem em apontar abrangência de bibliotecas de componentes existentes, identificar sistemas envolvidos no projeto ferroviário, além dos requisitos necessários de parametrização e o potencial de extração de quantitativos e de interoperabilidade.

\section{Resultados e Discussão}

A modelagem inicial foi feita no AutoCAD Civil 3D, no entanto, o mesmo se mostrou limitado em alguns requisitos, por exemplo, a visualização 3D que não permite representar equipamentos discretos. Mudando para o Revit, pensou-se em criar uma família simplificada que pudesse ser replicada em função do comprimento da via. Para o desenho do perfil do trilho, utilizou-se o AutoCAD, pois é uma ferramenta otimizada para modelos em 2D. Em seguida, modelou-se a família com lastro, dormente, placas de apoio e pastilha resiliente através da opção Extrusion. Uma vez que não há nenhuma aba relacionada à modelagem de elementos de transporte no Revit, a adaptação da opção Railing (Corrimão) foi essencial para o desenvolvimento da pesquisa. Outra solução relevante foi a opção Swept Blend na representação dos elementos do aparelho de mudança de via que possuem características geométricas complexas.

Uma limitação do Revit é a ausência da quantificação de materiais automática para as famílias do tipo Railing. Como forma de contornar essa restrição, adotaram-se parâmetros calculados em função do comprimento do trecho retilíneo ou curvo. Embora esse procedimento não seja o ótimo, foi uma solução simples e eficiente já que conhecemos as dimensões e quantificações da família que se repete a cada $0,60 \mathrm{~m}$.
Figura 1. Família com os elementos modelados.

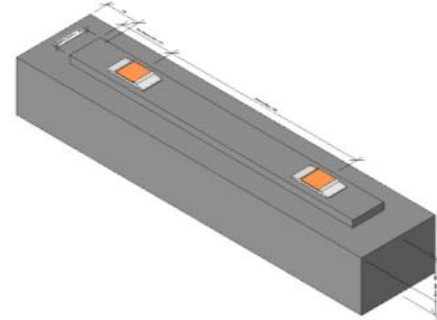

A ferramenta de quantificação do Revit se mostrou útil, eficiente e relevante para a pesquisa. A única ressalva é que os inputs (dados referentes às dimensões das famílias) são manuais na criação do parâmetro calculado, o que torna o processo passível de erro.

A exportação e importação dos arquivos IFC foram satisfatórias, sem necessidade de qualquer adaptação no processo. A opção escolhida na exportação foi a IFC $2 \times 3$ 2.0, pois é a versão certificada mais recente e, geralmente, suportada por outros sistemas.

Figura 2. Conjunto dos três trechos modelados
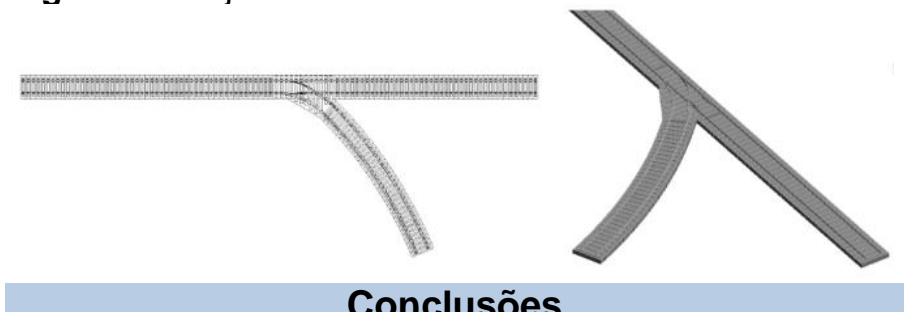

\section{Conclusões}

O uso de ferramentas BIM foi demonstrado na modelagem de trilhos de metrô. Algumas adaptações foram necessárias já que não existem módulos específicos para o transporte ferroviário no Revit. As ferramentas de quantificação e de exportação se mostraram eficientes e trouxeram resultados satisfatórios. Para projetos futuros, pode-se adotar um fluxo de trabalho que englobe as seguintes ferramentas: Infraworks, Inventor, Civil 3D, Revit, Navisworks e 3ds Max.

\section{Agradecimentos}

À Profa. Dra. Regina Coeli Ruschel, ao Eng. Daniel Mozart Saccomano do Metrô de SP, ao Eng. Pedro Luis Soethe Cursino da Autodesk e ao CNPq.

1 Paiva, Cassio Eduardo Lima de. Super e Infraestruturas de ferrovias: critérios para projeto. 1. Ed. - Rio de Janeiro: Elsevier, 2016. 